\title{
MANAJEMEN PENGEMBANGAN PROFESIONALISME GURU (STUDI MULTIKASUS DI MTS NU WALISONGO SIDOARJO DAN SMP ISLAM NU WALISONGO SIDOARJO)
}

\author{
Kholis Husaini \\ Universitas Negeri Surabaya
}

\begin{abstract}
The purpose of this study was to determine the management of professional development of teachers in MTs NU Walisongo Sidoarjo and SMP Islam NU Walisongo. Method multikasus qualitative study design, data collection through interviews, observation, and documentation. The results of the research are: 1) planning of teacher professionalism has been running well, 2) the organization of teacher professionalism is maximal, internally already solid and compact, 3) implementation of teacher professionalism goes according to plan but should more focus and emphasis on the needs and competencies of teachers, 4) supervision of teacher professionalism is well done, but the results of the evaluation have not been followed up to the maximum, 5) program professional development of teachers has been started but have not had the training program of scientific writings (practice significantly) and innovation work teachers, 6) Related to the professionalism of teachers of both schools need to improve and work hard to ensure that all teachers are held to have academic qualifications, competence of teachers, teacher certification and teacher allowances decent. For the teacher, should constantly improve professionalism to Achieve professional teachers and prosperous
\end{abstract}

Keywords: Management Development, professionalism of teachers, the study multicase

Abstrak: Tujuan penelitian ini adalah untuk mengetahui manajemen pengembangan profesionalisme guru di MTs NU Walisongo Sidoarjo dan SMP Islam NU Walisongo. Penelitian ini menggunakan metode kualitatif dengan rancangan studi multikasus, teknik pengumpulan data melalui wawancara, observasi, dan dokumentasi. Hasil penelitian adalah: 1) perencanaan profesionalisme guru sudah berjalan dengan baik, 4) pengawasan profesionalisme guru dilakukan dengan baik namun hasil evaluasi belum ditindaklanjuti secara maksimal, 5) Program pengembangan profesionalisme guru sudah dijalankan namun belum memiliki program pelatihan penulisan karya ilmiah (praktek secara nyata) dan karya inovasi guru, 6) Terkait dengan profesionalisme guru, kedua sekolah perlu berbenah dan kerja keras agar seluruh guru yang dimiliki memiliki kualifikasi akademik, kompetensi guru, sertifikasi guru, dan tunjangan guru yang layak. Bagi guru, hendaknya senantiasa meningkatkan profesionalismenya untuk mencapai guru yang profesional dan sejahtera.

Kata kunci: Manajemen Pengembangan, Profesionalisme guru, studi multikasus

Keterpurukan dunia pendidikan dipengaruhi oleh berbagai faktor, namun menurut hemat penulis, hal yang paling pokok yang mempengaruhi keterpurukan dunia pendidikan tersebut adalah faktor profesionalisme guru. Hal ini dapat dilihat bahwa dari dari data tahun 2002-2003 diberbagai satuan pendidikan untuk guru SD yang layak mengajar hanya $21,07 \%$ untuk negeri dan 28,94\% swasta, untuk guru SMP yang hanya layak mengajar $54,12 \%$ (negeri) dan 60,99 \% (swasta), sedang guru SMA yang layak mengajar 65,29\% (negeri) dan $64,73 \%$ (swasta) dan guru SMK yang layak mengajar 55,49\% (negeri) dan 58,26\% (swasta) (Samba, 2007; 10). Angka-angka tersebut masih sangat memprihatinkan. Pencapaian prosentase tertinggi guru yang layak mengajar hanya sekitar $65,29 \%$ yang hanya ada di Guru SMA negeri. Sedangkan guru-guru lainnya yang layak mengajar berada dibawah angka tersebut.

Dalam rangka itulah pemerintah kemudian berupaya untuk meningkatkan mutu 
dan kualitas pendidikan nasional lahirlah Undang-Undang Republik Indonesia nomor14 tahun 2005 tentang Guru dan Dosen. UndangUndang Guru dan Dosen lahir dengan tujuan untuk memperbaiki pendidikan nasional, baik secara kualitas maupun kuantitas, agar sumber daya manusia Indonesia bisa lebih beriman, kreatif, inovatif, produktif, serta berilmu pengetahuan luas demi meningkatkan kesejahteraan seluruh bangsa. Perbaikan mutu pendidikan nasional yang dimaksud meliputi, Sistem Pendidikan Nasional, Kualifikasi serta Kompetensi Guru dan Dosen, Standar Kurikulum yang digunakan, serta hal lainnya.

Profesionalisme guru yang menjadi tuntutan mutlak untuk mengangkat kualitas dunia pendidikan di Indonesia ternyata masih belum bisa diraih secara maksimal. Adanya program kompetensi dan sertifikasi guru ternyata tak mampu mengangkat kualitas kinerja guru dalam dunia pendidikan. Bahkan beberapa pihak menilai kompetensi guru pasca sertifikasi masih dianggap kurang menunjang kinerja guru dalam mengajar sehingga kualitas pendidikan Indonesia di dunia masih jauh tertinggal dan masih dianggap gagal melahirkan guru-guru yang cakap.

Berdasarkan data-data tersebut, menurut hemat penulis selama ini program-program pembinaan profesionalisme guru masih belum berjalan secara efektif. Kelemahan mendasar terkait profesionalisme guru tersebut terletak pada manajemen pengembangan dan pembinaan profesionalisme guru yang dilakukan di sekolah-sekolah..

Kegiatan-kegiatan yang dilakukan dalam managemen menurut Terry, dan Rue, (1986:9) secara umum ialah mencakup Planning (perencanaan), Organizing (pengorganisasian), Actuating (pelaksanaan) dan Controlling (control). Proses menajemen inilah yang dilakukan oleh pihak sekolah dalam rangka menciptakan profesionalisme guru.

Kebutuhan sekolah akan guru-guru yang profesional dalam menjalankan tugastugasnya adalah menjadi syarat yang mutlak dalam memajukan dunia pendidikan di sekolah tersebut. Demikian juga dengan sekolah MTs NU Walisongo Sidoarjo dan SMP Islam Walisongo Sidoarjo yang menjadi subjek dalam penelitian ini.
Melihat perkembangan kedua sekolah di atas, penulis mendapati bahwa secara kualifasi para guru sudah cukup baik, tetapi hal tersebut bukanlah satu-satunya jaminan yang menunjukkan profesionalisme guru. Di samping itu, penulis juga masih mendapati beberapa guru yang mengajar dan mendidik secara konvensional. Kedua sekolah masih belum melahirkan terobosan-terobosan model pendidikan dan pengajaran yang memberikan dampak cukup signifikan terhadap kualitas siswanya. Namun walaupun demikian, di sisi yang lain sekolah ini juga sudah bekembang dengan cukup baik.

Dari beberapa penjelasan itulah, penulis tertarik untuk melakukan penelitian dengan tema "Manajemen Pengembangan Profesionalisme Guru (Studi Multikasus di MTs NU Walisongo Sidoarjo dan SMP Islam Walisongo Sidoarjo)."

Manajemen pendidikan menurut Mulyasa, (2004:19-20) merupakan proses pengembangan kegiatan kerjasama sekelompok orang untuk mencapai tujuan pendidikan yang telah ditetapkan. Proses pengendalian kegiatan tersebut mencakup perencanaan (planning), pengorganisasian (organizing), penggerakan (actualiting) dan pengawasan (controlling), sebagai suatu proses untuk menjadikan visi menjadi aksi.

Menejemen pendidikan tersebut diterapkan dalam proses pengembangan profesi guru. Pengembangan profesi yang dimaksud adalah proses perubahan profesi guru dari kondisi yang tidak baik, kurang baik, atau baik, ke arah yang lebih baik lagi. Artinya adalah pengembangan profesi merupakan aktivitas perubahan kualitas seseorang menuju ke arah yang lebih baik dalam menjalankan profesinya.

Setiap guru dalam menjalankan profesinya harus secara profesional, akan tetapi kualitas guru yang ada kerap kali tidak memenuhi syarat profesionalitas, sehingga dibutuhkan pengembangan dan peningkatan profesionalitas guru. Pengembangan profesionalitas guru adalah merupakan proses pengembangan pelayanan yang diberikan oleh guru kepada peserta didiknya, pengembangan profesionalitas guru ini meliputi pengembangan pribadi, publikasi ilmiah, dan karya inovatif yang harus dimiliki oleh guru.

Tuntutan profesionalisme guru, sudah tertuang secara stubtantif dalam dalam 
Undang-Undang nomor 14 tahun 2005, yang mendefinisikan guru sebagai pendidik profesional dengan tugas utama mendidik, mengajar, membimbing, mengarahkan, melatih, menilai, dan mengevaluasi peserta didik pada pendidikan anak usia dini di jalur pendidikan formal, pendidikan dasar, dan pendidikan menengah. profesionalisme guru adalah cara kerja seorang pendidik (mendidik, mengajar, membimbing, mengarahkan, melatih, menilai, dan mengevaluasi peserta didik pada pendidikan anak usia dini di jalur pendidikan formal, pendidikan dasar, dan pendidikan menengah) dengan keahlian, kemahiran, atau kecakapan yang memenuhi standar mutu pendidikan nasional. Profesionalitas guru sering dikaitkan dengan empat faktor yang cukup penting, yaitu Kualifikasi akademik, Kompetensi Guru, Sertifikasi Guru dan Tunjangan Guru.

Dari beberapa penjelasan di atas, maka manajemen pengembangan profesionalisme guru adalah meliputi beberapa pembahasan yang secara rinci telah dijelaskan dalam sebelumnya, yaitu:

1. Perencanaan

pengembangan

profesionalisme guru, yaitu merupakan perencanaan yang dilakukan oleh pihak sekolah dalam upaya melakukan pengembangan profesionalisme guru, perencanaan ini meliputi programprogram, kegiatan, pelatihan, dan lain sebagainya.

2. Pengorganisasian pengembangan profesionalisme guru, yaitu merupakan proses pembagian tugas dan wewenang terhadap proses pengembangan profesionalisme guru, hal ini meliputi struktur, tugas, dan tanggungjawab.

3. Pelaksanaan pengembangan profesionalisme guru, yaitu proses realisasi program pengembangan profresionalisme guru.

4. Pengawasan pengembangan profesionalisme guru, yaitu proses monitoring dan control terhadap program pengembangan profesionalisme guru sehingga bisa mencapai tujuan-tujuan yang telah direncanakan.

5. Pengembangan profesionalisme guru, hal ini meliputi bentuk-bentuk program pengembangan profesionalisme guru, indikator keberhasilan program, dan target pencapaian tujuan program
6. Profesionalisme guru, merupakan bentukbentuk konkrit yang dihasilkan dari dampak realisasi program pengembangan profesionalisme guru. Dalam konteks ini, dapat diketahui berapa kondisi profesionlitas seorang guru.

\section{METODE}

Penelitian ini menggunakan jenis penelitian deskriptif yaitu penelitian yang diarahkan untuk memberikan gejala-gejala, fakta-fakta, atau kejadian-kejadian secara sistematis dan akurat, mengenai sifatsifat populasi atau daerah tertentu. Penelitian ini juga merupakan penelitian kualitatif yaitu penelitian yang menghasilkan data deskriptif berupa kata-kata tertulis atau lisan dari orangorang dan perilaku yang dapat diamati. Penelitian ini dilakukan MTs NU Walisongo Sidoarjo dan SMP Islam Sidoarjo Instrumen penelitian ini adalah wawancara yang menggunakan pedoman wawancara. Data Primer dalam penelitian ini diperoleh secara langsung dari wawancara dengan informan serta pengamatan (observasi) lapangan. Data sekunder dilakukan untuk melengkapi data primer yang diperoleh dari arsif dokumen atau foto. Wawancara, wawancara dengan informan. Observasi, pengamatan lapangan secara langsung Dokumnetasi, mengumpulkan arsip atau dokumen dan foto-foto

Penulis menganalisis data dengan analisis data model Miles and Huberman (1984 : 337) selama berada di lapangan. Telah dipahami bersama dalam analisis data kualitatif dilakukan secara interaktif dan berlangsung secara terus-menerus sampai tuntas sehingga datanya sudah jenuh. Aktivits dalam analisis data meliputi reduksi data, penyajian data, dan verifikasi atau sering dikenal dengan penarikan kesimpulan dan verifikasi.

Alat analisis dalam penelitian ini mengunakan daftar kejadian berupa rangkaian kejadian yang disusun secara kronologis. Rangkaian kejadian tersebut dapat dikelompokkan berdasarkan kriteria tertentu yang dalam penelitian ini dibagi berdasarkan fokus penelitian dan indikator-indikatornya. Dengan adanya daftar tersebut, peneliti dapat menjelaskan rentetan kejadian secara lebih terinci. Dalam penelitian ini, keabsahan data dilakukan dengan Kredibilitas / Derajat Kepercayaan (Credibility), Ketergantungan 
(Dependability), Konfirmabilitas / Kepastian (Confirmability),

\section{Hasil dan Pembahasan}

Untuk dapat menjalankan program pengembangan profesionalisme guru maka diperlukan perencanaan yang baik, mulai dari perencanaan program, peningkatan wawasan, pengingkatan kemampuan karya ilmiah, peningkatan anggaran, dan penyediaan fasilitas guru. Kedua sekolah baik MTs NU Walisongo Sidoarjo maupun SMP Islam Walisongo Sidoarjo secara keseluruhan sudah merencanakan pengembangan profesionalisme guru namun yang perlu ditingkatkan adalah alokasi anggaran untuk meningkatkan program dan fasilitas guru baik secara kuantitatif maupun kualitatif.

Program pengembangan profesionalisme guru memerlukan pengorganisasian yang baik, pengorganisasian pengembangan profesionalisme guru meliputi pembagian tugas, pembagian wewenang, kesatuan komando dan koordinasi. Secara umum, kedua sekolah baik MTs NU Walisongo Sidoarjo maupun SMP Islam Walisongo Sidoarjo sudah mampu mengorganisasikan pengembangan profesionalisme guru hal ini dapat dilihat dari kekompakan dan kesolidan dalam menjalankan program yang telah direncanakan.

Pelaksanaan yang baik dalam pengembangan profesionalisme guru meliputi kepemimpinan, pengarahan, komunikasi, dan motivasi. Kedua sekolah baik MTs NU Walisongo Sidoarjo maupun SMP Islam Walisongo Sidoarjo secara keseluruhan telah menjalankan pengembangan profesionalisme guru dengan baik indikasinya adalah terlaksananya program sesuai dengan perencanaan. Namun, yang perlu diperbaiki adalah belum adanya program yang lebih fokus dan menekankan pada kebutuhan dan kompetensi guru seperti penulisan karya ilmiah (praktek secara nyata) dan inovasi guru.

Selain itu diperlukan pengawasan dan pelaksanaan yang baik, pengawasan dan evaluasi pengembangan profesionalisme guru meliputi pelaporan secara tertulis, pelaksanaan evaluasi, pertanggungjawaban profesionalisme guru, pemberian penghargaan dan sanksi. Pengawasan dan evaluasi pengembangan profesionalisme guru sudah dilakukan oleh MTs NU
Walisongo Sidoarjo dan SMP Islam Walisongo Sidoarjo dengan baik. Namun, tindak lanjut evaluasi belum dilakukan secara maksimal.

Kedua sekolah baik MTs NU Walisongo Sidoarjo maupun SMP Islam Walisongo Sidoarjo secara keseluruhan telah menjalankan pengembangan profesionalisme guru. Program pengembangan profesionalisme guru yang sudah dijalankan meliputi pengembangan diri guru, peningkatan kemampuan penulisan karya ilmiah, peningkatan karya inovatif guru. Namun, yang perlu diperbaiki adalah belum adanya program penulisan karya ilmiah (praktek secara nyata) dan karya inovasi guru.

Dari sekian indikator profesionalisme guru yaitu, kualifikasi akademik, kompetensi guru, sertifikasi guru, dan tunjangan guru maka kedua sekolah baik MTs NU Walisongo Sidoarjo maupun SMP Islam Walisongo Sidoarjo perlu berbenah dan kerja keras agar seluruh guru yang dimiliki oleh kedua sekolah tersebut memiliki kualifikasi akademik, kompetensi guru, sertifikasi guru, dan tunjangan guru yang layak.

\section{Simpulan}

Berdasarkan penelitian dan fokus perencanaan pengembangan profesionalisme guru, pengorganisasian profesionalisme guru, pelaksanaan profesionalisme guru, pengawasan profesionalisme guru, pengembangan profesionalisme guru, dan profesionalime guru dapat diketahui bahwa secara umum manajemen pengembangan profesionalisme guru di MTs Walisongo Sidoarjo dan SMP Islam Walisongo Sidoarjo sudah berjalan dengan baik sesuai dengan teori rekruitmen dan seleksi. Namun, ada beberapa kendala yang perlu segera dilakukan upaya untuk mengatasinya yang berkaitan dengan pengembangan profesionalisme guru.

\section{DAFTAR RUJUKAN}

Amir, Almira, 2013, "Pengembangan Profesionalisme Guru Dalam Pembelajaran Melalui Model Lesson Study", Logaritma Vol. I, No.02 Juli, hlm 130-143 
Arikunto, Suharsimi. 2008. Dasar-dasar Evaluasi Pendidikan . Jakarta: Bumi Aksara.

Audet, Josée and Gérald d'Amboise, 2001, "The Multi-Site Study: An Innovative Research Methodology" The Qualitative Report, Volume 6, Number 2 June.

Benge, Eugene J., 1994, Pokok-pokok Manajemen Modern, (terj. Rochmulyati Hamzah), Jakarta; Pustaka Benama Pressindo.

Bogdan, Robert \& Sari Knopp Biklen. 1982, Qualitatif research for education: and introduction to theory and methods. Boston: Allyn \& bacon Inc.

Bukori, Muhammad, Dkk, 2005, Azas-Azas Manajemen, Yogyakarta; Aditya Media.

Bungin, Burhan, 2012 Analisis Data Penelitian Kualitatif (Pemahaman Filosofis dan Metodologis ke arah Penguasaan Model Aplikasi, Jakarta; Rajawali Pers.

Fathoni, Abdurrahmat, 2006, Manajemen Sumber Daya manusia, Jakarta; PT. Rineka Cipta.

Fattah, Nanang, 1996, Landasan Manajemen Pendidikan, Bandung; PT Remaja Rosda Karya.

Getteng, Abd. Rahman. 2011, Menuju Guru Profesional dan Ber-Etika, Cet. III; Yogyakarta; Graha Guru.

Hadi, Sutrisno 1990, Metodologi Research, Yogyakarta: Andi Ofset.

Hasibuan, Malayu S.P, 1990, Manajemen Dasar, Pengetian, Dan Masalah, Jakarta; CV. Haji Mas Agung.

Hasibuan, Malayu S.P., 2007, Manajemen Sumber Daya Manusia, Edisi Revisi, Jakarta; Bumi Aksara.

Manulang, M., 2002, Dasar-Dasar Manajemen, Yogyakarta; Gajah Mada University Press.

Miftah, Thoha, 1993, Perilaku Organisasi Konsep Dasar dan Aplikasinya, Jakarta; PT. Raja Grafindo Persada.

Miles, Mattew B., dan Huberman, A. Michael, 1984, Qualitative Data Analisys A
Sources Book of New Method, Baverly Hill : sage Publication.

Miles, Metthew B, A., Michael Huberman and Johnny Saldana. 2014. Qualitative Data Analysis, A Methods Sourcebook, Third Edition. Sage Publications, Inc.

Mulyasa, E., 2004, Manajemen Berbasis Sekolah; Konsep, Strategi Dan Implimentasi, Bandung; Remaja Rosda Karya.

Nazir, Moh,. Metode Penelitian, Jakarta: PT. Ghalia Indonesia,

Pidarta, M., 2008, Manajemen Pendidikan Indonesia. Edisi Revisi, Jakarta; Bina Aksara.

Poerwadarminta, W. J. S., Kamus Umum Bahasa Indonesia, cetakan ke-3, Jakarta; Balai Pustaka.

Riyanto, Yatim. 2010. Metodologi Penelitian Pendidikan.Surabaya : Penerbit SIC.

Sagala, Syaiful., 2008, Konsep dan Makna Pembelajaran. Bandung; Alfabeta.

Samba, S., 2007, Lebih Baik Tidak Sekolah. Yogyakarta; LKIS.

Sardiman, A.M., 2001, Interaksi dan motivasi belajar menggajar, Jakarta: Rajawali Press.

Satori, Djam'an, dkk., 2008, Profesi Keguruan, Jakarta; Universitas Terbuka.

Subardi, Agus, 1997, Pengantar Manajemen, Yogyakarta; UUP AMP YPKN.

Sugioyono., 2009, Metode Penelitian Kuantitatif, Kualitatif dan $R \& D$., Bandung, Al-Fabeta.

Suparno, P., 2004, "Guru Demokratis di Era Reformasi Pendidikan. Jakarta; Grasindo.

Suprayogo Imam, et.al., 2003, Metodologi Penelitian Sosial-Agama, Bandung; Remaja Rosdakarya.

Sutopo, HB, 2002, Metode Penelitian Kualitatif Dasar Teori dan Terapannya dalam Penenlitian, Surakarta; Universitas Sebelas Maret.

Syamsi, Ibnu, 1994, Pokok-Pokok Organisasi dan Manajemen, Jakarta; Rieneka Cipta. 
Tafsir, Ahmad, 1994, IImu Pendidikan Dalam Prespektif Islam, Bandung; Rosda Karya.

Terry, G.R. dan L.W Rue, 1986, Azaz-Azaz Manajemen (terj. Winardi), Bandun, Alumni Press.

Terry, George dan Leslie W. Rue. 2010. Dasar-Dasar Manajemen. Cetakan kesebelas, Jakarta; PT Bumi Aksara.

Usman, Husaini, 2006, Manajemen Teori, Praktik, Dan Riset Pendidikan, Jakarta; Bumi Aksara. 